\title{
3 Research Square \\ Pregnancy and childbirth during the COVID-19 pandemic in Poland: qualitative evidence from expert interviews.
}

\section{Paula Pustułka}

SWPS Uniwersytet Humanistycznospoleczny

Marta Buler ( $\sim$ mbuler@swps.edu.pl )

SWPS Uniwersytet Humanistycznospoleczny https://orcid.org/0000-0001-7205-4831

\section{Research article}

Keywords: COVID-19, pregnancy, childbirth, healthcare services, mental health, qualitative research, expert interviews

Posted Date: December 11th, 2020

DOl: https://doi.org/10.21203/rs.3.rs-48024/v3

License: (c) (i) This work is licensed under a Creative Commons Attribution 4.0 International License.

Read Full License 


\section{Abstract}

Background: The COVID-19 outbreak has significantly altered the provisions and shape of medical services for expecting mothers worldwide. In Poland, the country where pregnancy and childbirth are subject to comparably greater medicalization, those shifts are particularly tangible. This study aimed at capturing how maternal health professionals tackle care over pregnant and birthing women during a pandemic, highlighting possible long-term implications for the expecting and new mothers.

Methods: This is a qualitative study which addresses the themes around the emerging implications of the viral outbreak. Semi-structured expert interviews were conducted with 46 individuals working in either medical or adjacent sectors connected with reproductive medicine. In this analysis, 7 digital experts were excluded as observers rather than field practitioners. Among 38 interviews, 5 have been conducted with OB-GYNs, 13 with midwives, 6 with doulas, 14 broadly-conceived category of maternal support experts. The recorded data were input into thematic grids and meticulously transcribed prior to being subject to an inductive, thematic analysis.

Results: The findings revealed that the context of the heightened medicalization of pregnancy and hospital care during birth in Poland, resulted in strong restrictions and immediate fall back to a clinical care model. The majority claimed that the COVID-19 pandemic exacerbated the implications of the decades of Polish maternal health recommendations contradicting the WHO regulations. Professionals' anxieties concern limited access to services assisting women during pregnancies. While those linked to hospitals pointed out physiological risks, other maternal support experts drew attention to the effects of stress and uncertainty on maternal mental health.

Conclusions: Experts face various challenges when providing care to pregnant and birthing women in Poland. They underscore both the information chaos surrounding recommendations and procedures, and see the pandemic as a moment of reflection, mostly being vocal in their critiques of the over-medicalized Polish care model. The interviewed maternal health experts believe that the pandemic will have multifaceted consequences that are being exacerbated by a sudden cessation of extensive degree of medicalization during pregnancy, and a fallback to alienation during intervention-focused hospital deliveries.

\section{Background}

The novel coronavirus (Coronavirus disease 2019 - COVID-19) is a global public health emergency with no end date in sight. As with other sectors and groups, the COVID-19 outbreak has significantly altered the provisions and shape of medical services for expecting mothers worldwide In this article, we focus on how experts perceive and tackle challenges of providing care to pregnant and birthing mothers in Poland.

Polish context 
While the virus is not under control globally as of October 2020 (1), in Poland the situation has been tackled head-on, with the government-introduced lockdown and strict policies for medical facilities taking effect in early March 2020. It is important to note for this work that pregnancy and childbirth have been subject to comparably greater medicalization in Poland than in other European Union/ The Organisation for Economic Co-operation and Development (EU/OECD) countries $(2,3)$ prior to the outbreak. It has been elsewhere shown that overlapping medical and social shortcomings make pregnant women vulnerable in particular ways, introducing a condition of uncertainty and hindering women's ability to receive medical or social support $(4,5,6,7)$. Thus, the COVID-19 shifts of greatly limited availability of support translate to growing fears among the expecting mothers.

To give some contextual details about the pre-pandemic situation, Poland generally stands out in Europe regarding reproductive health and reproductive justice (8). While the maternal mortality ratio is extremely low (9) and perinatal mortality of children is decreasing, Poland's care standards are still strongly rooted in a clinical model. This is exemplified by the percentage of caesarean sections (C-sections) which has been stably growing from 1 in 5 in 2000, to peaking at 44\% of all deliveries in 2017 (10). Only 1 in 4 births ends in C-section in Europe (11 p.10), thus nearing the 1-in-2 ratio globally places Poland in third position, just behind Turkey and Korea (12). Medicalization is also evident from the rate of episiotomies which were carried out on $57 \%$ of women in Poland in 2015 , whilst this rate comparatively stood at $9 \%$ and $12 \%$ for Sweden and the United Kingdom, respectively (11).

Notably, home births and birthing centres are still a rarity in Poland, with only 136 out of 370706 (13) of all new-borns delivered outside of hospitals. The costs of non-hospital childbirth are relatively high (circa 800 EUR) and are not covered by insurance. Simultaneously, Polish women are also used to paying for the so-called 'nonessential' hospital care out-of-pocket. They privately finance their midwives, pay for 'family rooms' and so forth. This causes social cleavages, as only those with significant economic capital can afford better care during labour. Only in 2011, following two decades of advocacy efforts, Polish Ministry of Health introduced the first national Perinatal and Postnatal Care Standard (PPC Standard). The PPC Standard followed World Health Organization (WHO) recommendations, especially in relation to birthing companions, avoiding separation of mothers and new-borns post-birth, as well as giving women the right to choose a method and place of labour $(2,11)$. Governmental control nevertheless confirmed that numerous hospital wards were still not following the guidelines five years later (11 p. 10). The observed concerns ranged from infrastructural inadequacies like overcrowding, missing equipment or staff shortages, to issues related to women's dignity. Women's privacy and intimacy rights were not being respected and even though women should have access to childbirth anaesthesia covered by insurance since 2015, not having an anaesthesiologist on staff makes this pain management option unavailable for many women (11). The Polish PPC Standard was then expanded in 2019, with the now imposed duty to monitor the mental state of women during pregnancy and in the postpartum period. This falls on healthcare providers, mainly midwives (3). At the same time, a large-scale study by Baranowska et al. (14) found that $81 \%$ of women in a sample of 8378 experienced violence or abuse during their childbirthrelated hospital stays in Poland, long after the Standard was put in place. Most recalled physical discomfort during procedures, inappropriate comments and violations of privacy. 
It appears that the epidemiological threat exacerbated tensions between WHO recommendations and more women-centred care led by midwives, and hospital/OB-GYN (obstetricians and gynaecologists) care bounded by legal frameworks. WHO recommendations (15) focused on ensuring high-quality antenatal, intrapartum and postnatal care, inclusive of safeguarding well-being of mothers and new-borns. Moreover, the WHO guidelines called for skin-to-skin contact post-delivery, encouraging breastfeeding for so-desiring women. They did not speak to the cessation of family member's presence, however, WHO still left the final decision in the hands of national and local consultants.

In the latter realm, state-run clinics and private practices in Poland were subject to a national lockdown as of March 13. A ban on hospital visitations was introduced shortly after on the 20th of March 2020, with family births forbidden as well. Poland quickly fell back to a narrow model of the clinical rather than a holistic antenatal and perinatal healthcare. According to the Childbirth with Dignity Foundation (16), which has been at the forefront of fighting for granting subjectivity and agency to birthing mothers in Poland since 1994, this was a sudden imposition, potentially contributing to trauma being experienced by women who were not at all prepared for this shift.

Neither Polish Society of Gynaecologists and Obstetricians, nor the National Neonatology Consultant, issued changes to their recommendations in the face of emerging evidence $(4,5,6,7)$ from the medical community worldwide. This signified a growing dissent from non-profit organizations and the Polish Ombudsman Office. At the beginning of May 2020, Polish Society of Gynaecologists and Obstetricians slightly revised restrictive recommendations to allow one birthing companion (17). However, there have been reports about difficulty in actually meeting the requirements for the birth partner who is supposed to have an up-to-date (not older than 5 days) and negative outcome of the COVID-19 PCR test (Polymerase Chain Reaction test). This is hard to do not only in the light of the unpredictability of the exact labour date and, more importantly, due to the limited accessibility of PCR testing in Poland.

After two months of the aforementioned limitations, the National Health Fund (NHF, 18) announced that women have a right to a birth companion regardless of the pandemic. In July 2020, the authority conceded that requiring an up-to-date COVID-19 PCR test is irrational. To meet the upheld recommendations, NHF guarantees additional money for protective gear. In addition, the accompanied birth can only happen if the hospital facility has enough single-occupancy en-suite delivery rooms. If granted the right to accompany a birthing woman, one person may stay for up-to two hours after birth only. Nonetheless, no other rules concerning hospital visits, skin-to-skin contact or breastfeeding have been altered by October 2020. Furthermore, for pregnant women who either test positive for the novel coronavirus or are suspected of having contracted the virus, Polish National Consultant continues to enforce maternal and new-born isolation, as well as no breastfeeding.

Growing concerns and expert views on COVID-19 and pregnancy: identifying the gap 
Strong focus on clinical recommendations regarding care for pregnant women with COVID-19 are crucial, yet they might obscure non-immediate concerns for broader populations of pregnant women. For example, in an Italian case study, Micelli and co-authors (19) showcase that $37.3 \%$ of those who planned to have a child before the pandemic have changed their mind. Their decision was related equally strongly to economic worries and possible health consequences of COVID-19 on the pregnancy. In this context, stress during pregnancy is a highly concerning public risk exacerbated by the outbreak. Corbett and coauthors (20) found that pregnant women experience increased anxiety about their immediate family, older relatives and unborn baby, while Viaux and team (21) explicitly expect the rate of postpartum depression in the general population to rise up from the current $15 \%$ in response to the lockdown measures. As argued by Mirzadeh and Khedmat (22), 'in nulliparous pregnant women, the adverse mood symptoms accompanied by childbirth fear may have irreversible effects on mother and child health', thus health management and monitoring of wellbeing should not only concern late pregnancy but also the first two trimesters.

Recommendations by Rocca-Ihenacho and Alonso (23) favour decentralized midwife units and community birthing support. Durankus and Aksu (24) surveyed 260 pregnant women in Turkey and found that $70 \%$ believed that the pandemic will impact on their pregnancy, with $35 \%$ scoring higher than average on three depression and anxiety scales. It is important for the Polish case that Topalidou with co-authors (4) specifically criticize early responses and clinical interventions in the form of separating mothers from infants post-birth and discouragement of breastfeeding. This is because feelings of inadequacy and shame about motherhood cause increased self-blame and make young mothers even more prone to postpartum depression (25). This was confirmed for the COVID-19 times in a qualitative study by Das (6) who interviewed 14 women in Britain during their perinatality in May 2020. She notes instances of blanket social distancing measures due to virus-related anxiety, resulting in missing routine care appointments. The interviewed women felt cheated and devoid of the joy of motherhood, reporting feelings of guilt and sole sense of responsibility caused by partners' exclusion from antenatal preparations, often linked to mental struggles of young fathers. While digital support provided respite, it was often deemed insufficient.

Few studies focused on the perspectives of health professionals. A quantitative, international and nonrepresentative survey of 714 maternal and new-born healthcare providers was conducted by Semaan and team (26) in April 2020. These voices from the field expectedly indicate that professionals in high-income countries had a higher likelihood of being informed about guidelines, as well as better access to infrastructure (e.g. dedicated COVID-19 maternity suites). Across the board, stress levels of professionals increased, often because of staffing shortages and commuting challenges. Main concerns related to adverse outcomes caused by limited antenatal care provisions, fewer outpatient visits, cessation of having birth companions' support, mother-new-born separations and postponed immunizations for babies. At the meta-level, studies $(4,26)$ emphasize that hard-won victories in empowering birthing women can easily be lost by a high susceptibility of maternity care services to the clinical protocols during emergencies, which we here examine in the particular context of high medicalization in Poland $(2,11,13)$. 
Considering the above, especially the junction of the Polish medicalized maternity care and the emerging research on birthing during COVID-19, this study's research question was: How do maternal health professionals in Poland tackle the care over pregnant and birthing women?

\section{Methods}

\section{Study design and participant recruitment}

The study represents one of the components within a broader qualitative research program focused on motherhood and underway at the at the (Youth Research Center of the SWPS University since 2018. Specifically, "Transition to motherhood across three generations of Poles. Intergenerational longitudinal study" [GEMTRA] project ${ }^{[1]}$ is here complemented by the "Mother 360 degrees - A journey to motherhood in contemporary Poland according to experts" [Mother 360]) study ${ }^{[2]}$. Sharing topical focus and methodological premise, the two components of this research programme cross-sectionally address the process of becoming a mother from a number of perspectives, ranging from expecting mothers, through their relatives and antenatal non-medical support providers, to health professionals. For the sake of this article, the analysis is limited to the interviews with experts- practitioners in the field of reproductive medicine, as well as antenatal, perinatal and postpartum care services.

Mother 360 was a qualitative study in which semi-structured in-depth individual interviews (interview guide, translated into English, has been included in the appendix) were conducted with medical (incl. OBGYNs, midwives), digital (parenting bloggers) and supporting health professionals (incl. doulas, psychologists, physiotherapists). Interview guide initially consisted with four thematic blocks: professional path, parenthood in expert's lens, family discourse about family, adulthood in expert's perspective. As we were preparing guides for expert interviews, the first COVID-19 cases were being reported in Europe. Therefore, we have included additional research question, namely "What are the observations, practices and predictions of maternal experts in the field of prenatal, perinatal and postnatal model of care in the time of the pandemic? This resulted in including COVID-19 related themes: the impact of pandemic on the overall situation of pregnant women pregnant women's physical and mental condition, as well as their birthing plans. Researchers could follow-up with additional questions that were not included in the interview guide.

\section{Participants and data collection}

Study participants were selected deliberately, with attention being paid to heterogeneity of the interviewees with regards to profession, age and, most importantly, place of work. The sample is biased towards women, given the gendered labour market sectorization. The recruitment techniques were reliant on letters to prominent figures of maternal support, adverts on social media, as well as personal contacts of the research team, followed by a snowballing strategy.

In total, 46 interviews were carried out across various categories of experts: medical, digital and supporting professions. For this analysis, we excluded the digital experts as those are seen as observers 
rather than practitioners in the field. Finally, 38 interviews were analysed including those with: 5 OB-GYNs, 13 midwives, 6 doulas and 14 professionals. All but four participants were women. The respondents were born between 1960 and 1991 (average age 38,2) and had higher education.

With a lockdown in place, the participants were interviewed through digital methods, with semi-structured, individual interviews conducted online (e.g. via Skype WhatsApp, Messenger) or - in some cases - over the phone. Besides receiving an information package, prior to the commencement of each interview, the researchers have informed participants once again about the study, as well as acquired consent through verbal confirmations in response to statements about anonymity, right to withdraw etc. A team of experienced qualitative researchers followed the interview guide when collecting the empirical material. The interviews were carried out in April and May 2020 and lasted 1.5-hours on average.

\section{Data analysis}

Interviews were audio-recorded and then input to framework grids by the researchers, as well as meticulously transcribed verbatim by an external subcontractor bound by a dedicated NDA (Nondisclosure agreement). Framework grids and transcripts were subject to thematic and cross-sectional analysis (see: Figure $1 ; 27,28$ ), with a data analysis workshop attended by the entire research team. The collaborative work with data helped ascertain intersubjectivity and cross-validation of the emerging saturation and patterns of meaning.

Source: own elaboration based on Saldana (29)

The data deemed relevant for this particular topical analysis was extracted with extended excerpts for subsequent recoding, then refined and finalized by both authors. Under the interpretative paradigm, data analysis led to a delineation of four main themes. Those were: 1) medicalization of pregnancy care and childbirth in Poland, 2) getting pregnant during a pandemic, 3) pregnancy care during COVID-19, 4) birthing during a pandemic. The long-term consequences of pregnancy and birthing during pandemic of COVID-19 were not a separate theme, but rather emerged as cross-cutting from a cross-sectional analysis of the data coded under 2-4. As such, it was also incorporated to the thematic analyses of the discussed phenomenon.

${ }^{[1]}$ This work was supported by the National Science Center under Grant Sonata 13 No 2017/26/D/HS6/00605.

${ }^{[2]}$ This work was supported by the statutory funds awarded by the Institute of Social Science at the SWPS University under the grant no. SUB/INS/2019/8.

\section{Findings}


Relatively little is known about pregnancy care in Poland from a qualitative perspective of experts, thus it is valid to first highlight the broader context of medicalization from the perspective of healthcare professionals:

At a big conference in Poland, there was a comparison of pregnancy care in Poland versus (...) some rich countries in Western Europe (...) We do so many tests! A lot of ultrasound exams, while there are some countries where there are only two throughout the entire pregnancy. Midwives manage pregnancies. I think our model is highly and strictly medicalized. (3_KE, OB-GYN in a hospital \& at a private clinic[1])

Our study shows that Polish experts vary in their awareness and evaluation of medicalization of pregnancy and birth. On the one hand, OB-GYN respondents were expectedly keen on leading pregnancy as sole decision-makers. They saw privatization and medicalization as underpinnings of optimal care and outcomes, especially during birth:

I think giving birth in a hospital is an absolute must, securing surgery suites, medication, adequate tools. Birthing homes are perhaps a cool idea, the conditions are homier, but they need to have hospital backup (...) And there's the Health Ministry's standard, it has systematized (...) and legally confirmed the schedule of visits and care. (10_KE, OB-GYN in a hospital)

On the other hand, midwives, doulas and specialist consultants like psychologists saw the risks of such a model, especially in the absence of a holistic approach, limited input from other professionals and disenfranchisement of patients. They typically contested the power of doctors being as far-reaching as it is at present:

In Poland we continue to have this inflated medical aspect (...) I think there is this massive need to medicalize, the inducements of births, redressing normal labour into frames where two hours pass and then there goes a caesarean and the thing is over. I think we should draw more from the evidence-based Western medicine, knowledge based on scientific facts about perinatal care. In Poland we are really so behind. This is evident also with the pandemic situation. In the interest of women, we need to look more to the West. (14_KE, midwife at a hospital \& at a private practice)

As above quotes show, perceived high medicalization of pregnancy and birthing in Poland is not unequivocally regarded as a negative phenomenon. Expectedly, those working in the strictly medical field argued that the medicalized health system makes the process safe for a mother and a foetus/ new-born, with safety guaranteed by doctors and midwives. However, especially in the opinions of those who often see negative implications of medical interventions, the current overmedicalization may be conducive to denying patients' agency, causing wellbeing-related problems noticed by maternity experts.

Getting pregnant during a pandemic

The experts in the Mother 360 project have been observing growing fears that impacted on the preconception processes and reproductive decisions of women (19). OB-GYNs, following the Ministry of Health recommendations, stopped provisioning fertility treatments and urged postponement of 
pregnancy plans during the pandemic. They drew on the fear stemming from the unknown consequences of this virus for mothers and unborn children:

Women who planned to have a child are scared. Doctors simply advise them not to get pregnant because not much is known about the virus. It is impossible to say how it could influence the foetus during the orthogenesis, when all organs are formed. One does not know if the baby would be healthy. Both pregnant women and those who planned on getting pregnant, and the birthing women, they are all negatively affected by this situation. (48_KW, physiotherapist at a private clinic \& at a private practice)

Importantly, interviewees anticipate that the pandemic might get worse and last long. This especially holds as the impending recession factors begin to overlap with the weakening conviction about the economic viability of one's reproductive plans (19), on which one interviewee claims that "many women will alter their plans due to economic reasons" (39_MW, physiotherapist with own private practice). At the same time, experts argued that not all women have a privilege of holding off, referring especially to those struggling with infertility and being in their late 30 s or early 40 s. While they might be in the risk group, the desire to have a baby appears stronger than COVID-19 fears:

There are these women who are older, born in the 70s and 80s. When it comes to pregnancy, especially the first one, they feel a breath of time on their necks and don't believe they can wait. They have been trying for a while and they simply think that - virus or no virus - they will get pregnant. This is their decision and even though our recommendations are clear on discouraging getting pregnant, it is also true that our experiences with corona-virus in early pregnancy are non-existent. (10_KE, OB-GYN at a hospital)

The uncertainty connected with COVID-19 - according to maternity experts - brings on stress and anxiety among women who are considering conception.

\section{Pregnancy care during COVID-19}

According to experts who interact with pregnant women on a daily basis, uncertainty and information chaos are pervasive, especially as recommendations and practices vary between WHO, national experts and local practitioners. Inconsistencies are the source of nervousness:

There is so much news in the media, it's a giant mess. In Poland we do not cope with information well and we have recommendations differing from what is happening abroad, not in line with WHO. If someone reads English and has friends abroad, they might get completely lost, ask themselves what does it mean that someone else could do something but they can't, each doctor says something different. We're feeling lost, it's a giant mess. (5_KE, midwife/ breastfeeding advisor at a private clinic)

The confusion about decisions and their ownership does not change the experts' perception of women as facing an injustice. Recommendations aside, expecting women are portrayed as made highly vulnerable by the pandemic, also because their carefully planned antenatal activities have been upended from one day to the next: 
This is very stressful. I see young women being completely cut off from doctors, from consultations, from ultrasounds, various control visits. They are really affected by this and the fact they cannot see anyone, can't access (services), everything was cancelled. (34_KW, sling advisor at a private practice)

The access to various medical procedures, which warranted feeling safe, has been cut off. According to experts, women were expected to trust the professionals fully before the pandemic, so erasure of support required sudden switch to alternative advice or practices: be it online or though self-assessment. The medicalization before the pandemic was an everyday experience in Poland, so it can be argued that women were not accustomed to self-reliance. As representatives of supporting professions indicate, without any preparation, pregnant women were left alone with neither professional support nor knowledge about norms:

Doctors simply closed their clinics from one day to the next, which for me was really unacceptable. I simply cannot imagine leaving a pregnant patient, just saying that well, it's closed now, go find yourself someone else. (41_KW, doula with a private practice)

There was an observable pattern that the closer the expert was to clinical care (e.g. working in a hospital ward), the more concerns about adverse medical outcomes they voiced. Particular attention was drawn to those who require specialist care but were left alone without any options, abandoned in the middle of the process:

Women have restricted access to doctors and examinations. There are those who have high-risk pregnancies, need to be overseen by a diabetologist, endocrinologist - these visits were made much more difficult (...) Some things cannot be done well in an online visit. For instance, the half-point ultrasound, it would be unthinkable to have it not happen at the right time. Cancelling those visits, I don't know but I think that we will see women suing because their right to healthcare is being restricted. I do not believe these key appointments should be cancelled. (7_KE, midwife with a private practice)

Consequently, the interviewees predict that the upcoming waves of births and new-born cohorts will be negatively affected by the pandemic:

I see my patients and in August and September we will have a brood of crying children, children hard to regulate because women are loaded with cortisol. I understand that birthing classes happen (virtually) but we are social beings and this online relationship is simply not sufficient for critical situations. (44_KW, physiotherapist with a private practice)

As Polish medical professionals work with very tight and extensive schedules as regards pregnancy care, they underline possibly serious health implications. Moreover, the professionals indicate that both sudden decisions and a prolonged social lockdown might affect parturition:

If a woman is pregnant and already has small children that she needs to isolate and they cannot go out, then l'd imagine that the perinatal risks are going to be higher for the new-born. This pregnancy is then exhausted. It is not a physiological pregnancy, even if it has a physiological presentation. The 
environmental factors have an incredible bearing on how the pregnancy unfolds, the well-being of a foetus and the birth itself. (44_KW, physiotherapist with a private practice)

However, decisions connected with cancelling visits at doctor's offices are perceived through a dual lens: the well-being and medical consequences for a woman and her unborn child, and possible implications of a lockdown on the maternity support sector and professionals more broadly, i.e. when specific practice or specialist might not be able to run their business for a longer time during the lockdown. The tensions between doctors, midwives, doulas and other experts are more vivid during the pandemic, yet also, collaterally to the market lockdown and closing of outpatient clinics and on-site services, telemedicine and online provision of classes has blossomed quickly:

Pandemic resulted in a speedy development of telemedicine, which is how I work now. It turns out that even pregnancies can be managed through telemedicine (...) Even though we were critical of those methods, the pandemic shows the usefulness of digitalization, introducing e-prescriptions and medical leave confirmations online. We might not yet realize the benefits it gives us, the fact that it is (now) permitted. Even my private practice can be run this way because I have all documentation online. (3_KE, OB-GYN at a hospital \& at a private clinic)

In a peculiar manner, the lockdown challenges the typical medicalization of pregnancies in Poland, wherein women usually visit their managing doctors every 2-3 weeks. For some of the experts, pandemic served as a means to reflect on what is truly needed, limiting personal visits only to absolute emergencies:

It is indeed easier not to drag the patient for a face-to-face examination, it is enough to give some advice or consult about the results of a test online (...)The patients are no longer trying to push for a hospital stay, we don't see one million consultations in the ER. From this perspective, it became much calmer. A woman would think 'OK, I am not dying, nothing serious is happening. So maybe there is no reason to run to the hospital or the doctor's office'. (10_KE, OB-GYN at a hospital)

From this dual perspective, it can be observed that experts other than OB-GYNs have their doubts towards inaccessibility of health care services. They might judge women as not accustomed to being experts in their own pregnant bodies. The expert, therefore, link uncertainty and lack of preparations through medical consultations with anxiety and stress for expecting mothers and their babies. At the same time. some experts became protagonists of limiting face-to-face meetings with pregnant women.

\section{Birthing during pandemic}

For those women who are planning to give birth in hospital and more or less follow the medicalized way of childbirth, the pandemic has several implications. Midwives and other experts who participated in the research pointed out that a clinical model not only does not improve outcomes but actually implies that non-evidenced-based actions are allowed during a national lockdown perceived as an emergency. 
The (birthing companion ban) will have a tremendous impact. I have a patient who cannot imagine giving birth in a different setting, without her husband present for this crucial moment. (Women) are at the hospital wards alone, nobody is allowed to visit them. If a woman experiences something bad, encounters a difficult event at the hospital in connection to birth, then she will be facing a much more difficult situation due to being alone with it. I think this is the main negative impact, (pregnancies and births) became psychologically harder. (6_KE, midwife at a a hospital)

The Polish experts seem to have limited access to knowledge, so the distributed information and soundness of recommendations varies on a case-by-case manner:

The national consultants for midwifery and neonatology issued a peculiar update last week, saying that there was never a ban on accompanied births at all. It seems that the restrictions were introduced by the hospitals, which is not true because these came from the consultants' recommendations. Factually, we followed 'recommendations' though no legal, banning act was introduced. At the same time, the advice from regional and national consultants was to stop allowing birth companions (13_KE, midwife at a public clinic)

While midwives, doulas and psychologists/therapists tended to worry about women's fears, they also proclaimed interesting benefits of the pandemic re-empowering Polish women and posited, that expecting mothers gained stronger convictions about their own capabilities:

Women gained more self-confidence and trust towards their own judgement, observing their bodies, their pregnancies and their babies, it's all very common-sensical now. (10_KE, OB-GYN at a hospital)

However, such an optimistic perspective is rather an exception among the experts and seen as a potential that would need to be realized in a longer-term, the more immediate concerns and predictions relate to a new wave of medical interventions resulting from the increased anxiety and stress. The most common predictions are connected with expecting

It is very difficult now. More so because pregnancy and the perinatal period should not be marked by anxiety. The births will not start, they will not begin and they will need to be induced. We will have thousands of $C$-sections. From $C$-sections, we will have children separated from mothers. This will be terrible. As usual, women will be the victims. (45_KW, doula with a private practice)

Decisions about caesareans were, subsequently, connected with predicted or real problems with physiological childbirth and tied back to the explicit fallback to a clinical model. Experts - medical and support professionals alike - asserted that hospital doctors regained absolute power, undoing the work towards safeguarding women's dignity during birth:

Situation of pregnant women changed dramatically because we have horrendous consultants, useless, 60-year-old geezers who decide how women are supposed to birth children (...) And they completely ignore WHO recommendations. (Pandemic) changed women's situation because their visits are cancelled 
and this causes anxiety. Everyone was already taking away their competence, now they suddenly have none left. (45_KW, doula with a private practice)

In connection to what Rocca-lhenacho and Alonso (23) argued in the face of the pandemic more broadly, Polish experts also wondered about the potential to challenge medicalization:

Women who wanted to give birth at home, those who are very aware and have their own midwives, well, they are still well taken care of, nothing has changed. This really shows the dissonance as to how a hospital was supposed to be this safest place, but now we see it is absolutely not. Women who rely on midwives, they have continuous care and will give birth at home, naturally. (5_KE, midwife/ breastfeeding advisor at a private clinic)

In this context, the epidemiological situation may once again reframe the debate on what the best place and model for giving birth might be.

[1] Every quote is described with an interview number, as well as profession and further information on the place of work.

\section{Discussion And Conclusions}

This paper offers qualitative evidence from 38 expert interviews conducted at the key period of 2020, immediately following the introduction of social and healthcare access restrictions linked to the pandemic in March 2020 in Poland. To first answer the main question of this article, we have demonstrated that experts supporting pregnant and birthing women in Poland perceived the pandemic as a major hurdle to providing optimal reproductive care. Our analysis cross-sectionally pointed out to information chaos that surrounded services for pregnant and birthing women. This sense of uncertainty - due to misinformation and lack of clear guidelines - applies not only to women who are about to become mothers but also, vitally, to the experts themselves. Similar to Semaan and team (26), our study shows from a qualitative perspective that experts are stressed and confused, calling for more research on best practices and strategies for tackling risks associated with COVID-19 and pregnancy.

Our thematic analysis focused on a specific case of Poland, typifying a regime marked by strong medicalization of pregnancies and births, still often pinpointed as an example of a country where progress in general indicators and introduction of the Standards did not translate to ensuing reproductive justice and guarantees of rights and dignity for birthing women $(2,8,11,14,16)$. According to the interviewed experts, yet regardless of whether they embraced the pre-pandemic model of care, a high degree of medicalization makes it that much harder for the Polish expecting mothers to handle the ongoing epidemiological situation, both physiologically and mentally (4). On this note, the majority of our experts supported the claims from other research $(4,5,6,7,20,21,22,23,24,26)$ on the clinical model of antenatal and perinatal care during COVID-19 overlooking the well-being dimension. They drew attention 
to both perceived disenfranchisement and high-levels of stress among women who are users of the care services and support normally provided by the experts.

In fact, the challenge the experts saw in relation to tackling the pandemic and pregnancy junction often concerned also those women who were at the conception planning stage, since many of the interviewed professionals stopped providing fertility-related treatments and services. As for pregnant women, the interviewees in favour of a more holistic pregnancy care saw a value in women becoming more selfobservant, yet also had doubts if sudden reflection can alleviate the fact that Polish women were led to trust in the medicalized model. Moreover, nearly all experts worried about the weakening attention to birthing women's dignity in the current state of emergency, which corresponds to the pre-existing challenges to this aspect of childbirth experiences in Poland $(2,11,14,16)$.

The staff of private clinics and specialist practices also underscored that doctors regained full power over birth, especially when non-hospital births remain a marginal fraction of all labours and the Standards of care are not followed, even when no global pandemic rages $(10,11,12,13,14,16)$. According to the interviewed experts, the already high number of medical interventions during childbirth is likely to increase as women are unable to benefit from advocacy done on their behalf by birthing companions, support caregivers or visitors and family members. Our data supports initial findings about telemedicine offering some form of replacement for the pregnant women (6), yet many experts - particularly doctors and those working at the hospitals - remained sceptical about their usefulness. In the interviewed experts' opinions, the pandemic acts as a litmus test of the healthcare services in Poland, both in terms of how the care and support for pregnant and birthing women is provided or organized, and as regards to identifying an element of a caring model that constitutes its base. Our findings more broadly demonstrate that the crisis challenges what experts knew and believed about the Polish antenatal and perinatal care system before COVID-19. In their view, a high-degree of medicalization makes it, paradoxically, somewhat less prepared for a condition of a prolonged hyper-uncertainty caused by the novel coronavirus-related restrictions and measures. As the interviewees underline, women were accustomed to constant (biweekly) control from doctors, yet had to face their sudden unavailability, which often resulted in significant anxiety and stress.

At the very same moment of divesting women of support in the crucial antenatal period, the childbirth experience itself defaulted to women having no agency. In that sense, a period of de-medicalization during pregnancy is now followed by the reinforcement of the power ascribed to hospital personnel during a medicalized birth. As of November 2020, Polish women are affected by national guidelines that are not only largely noncompliant with the WHO (15) recommendations, but also bypass the Polish Standard of Perinatal Care. It can be said that the existing model rooted in a strong position of the OBGYN and centrality of hospital as a birthing place, has been failing Polish women in the COVID-19 context according to the interviewed experts. In that way, the evidence strengthens the conclusions of the existing work on the challenges of the Polish system's inflexibility and lack of alternative options, paired with the already considerable disregard towards the WHO guidelines on maternal wellbeing $(10,11,12,13,14,16)$. 
As the presented results stem from a qualitative study conducted early on during the COVID-19 pandemic, it is highly recommended to pursue further research on this topic. Firstly, a quantitative and ideally crosscountry approach is needed to gauge prevalence of the noted themes, as well as to check how the Polish over-medicalized system compares to other country-contexts. Secondly, a longitudinal lens is advisable for checking whether the described attitudes are maintained or shift over time as the epidemiological situation unfolds into the late 2020 and 2021 . While the project has limitations rooted in the qualitative nature of the work - mostly the relatively small number of interviews and the non-representative nature of participant recruitments, it leverages rich and saturated data to highlight main concerns and themes raised by the maternal health experts in relation to pregnancy and birth during COVID-19 in Poland.

In terms of recommendations for practice, our study supported the argument for an introduction of guidelines (26), but extends the scope of the current target group. First, we posit that recommendations on care optimization should not only focus on women who were indeed diagnosed with COVID-19 during pregnancy, but also on those who are considering reproduction and undergo healthy pregnancies without being infected. At present, this group of women seems to experience somewhat invisible vulnerability they have limited access to services, yet are not subject to social assistance. We argue that revisions of pregnancy and care guidelines that account for the pandemic and offer safe and reasonable solutions of alternative support should be proposed and implemented across various sectors of expertise. In future research, we advise to explicitly consider the pre-pandemic state of pregnant and birthing women in a given healthcare regime to highlight how the level of medicalization and the perceived delegation of support to experts impacts on the experiences of pregnancy and birth during COVID-19 lockdown. In that sense, we believe that more knowledge-exchange and holistic guidelines on supporting pregnant women and new mothers with alternative care models during global health crises need to be developed, especially in high-medicalization regimes like Poland.

\section{Abbreviations}

COVID-19 Coronavirus disease 2019

EU/OECD European Union/ The Organisation for Economic Co-operation and Development

C-section Caesarean section

WHO World Health Organization

PPC Standard Perinatal and Postnatal Care Standard

OB-GYN obstetricians and gynaecologists

PCR test Polymerase Chain Reaction test

NHF The National Health Fund 
NDA Non-disclosure agreement

\section{Declarations}

\section{Ethics approval and consent to participate}

The project received ethical approval from the Ethics Committee for Empirical Research with Human Participants at the SWPS University. Verbal, recorded consent to participate was given by participants, but written consent was not required by the ethics board since that would be the only documentation tying the participant to the study.

Consent details: participants were provided with a Study Information Summary and consent summary outlining the background and purpose of the study, background of the researcher, eligibility criteria, what participation in the study would involve, the right to withdraw from participation at any time, and the storage and disposal of data collected. Contact details of the researcher along with clear guidelines on how privacy and confidentiality would be protected were also provided.

\section{Consent for publication}

All identifying information was removed and therefore permission to publish was not needed yet, interviewees were informed that collected data in anonymized form will be published.

\section{Availability of data and materials}

The datasets generated and/or analysed during the current study are not publicly available due to containing Plls in raw transcripts. They are available from the corresponding author on reasonable request.

\section{Competing interests}

The authors declare that they have no competing interests.

\section{Funding}

This study was partly funded by the statutory funds awarded by the Institute of Social Science at the SWPS University under the grant no. SUB/INS/2019/8 and by the National Science Center Poland (Sonata 13 grant No 2017/26/D/HS6/00605). The funding bodies did not have any impact on the design of the study and collection, analysis, and interpretation of data. The grants have been won in biddings and authors have a full freedom to conduct the research. If the article is accepted, the cost of publication would be covered by one of the funding bodies.

\section{Authors' contributions}


PP contributed to the design, coordinated and carried out the interviews and data analysis and drafted the manuscript. MB participated in the design, carried out the interviews and data analysis and supported the process of drafting the manuscript. Both authors read and approved the final manuscript.

\section{Acknowledgements}

The authors would like to thank and acknowledge the participants for their valuable contribution and willingness to participate in this study and the research team who also participated in conducting interviews with experts.

\section{Authors' information (optional)}

Affiliations

\section{Youth Research Lab, SWPS University, Warsaw, Poland}

Paula Pustułka

Marta Buler

\section{References}

1. WHO [Internet] World Health Organization. Weekly Operational Update on COVID-19 [cited 2020 Oct 2]. Available from https://www.who.int/docs/default-source/coronaviruse/situationreports/20200928-weekly-epi-update.pdf?sfvrsn=9e354665_6

2. WHO[Internet] World Health Organization. Raising the voices of pregnant women in Poland. 2015 Aug[cited 2020 Jul 14]. Available from: https://www.who.int/features/2015/childbirth-dignitypoland/en/

3. Magdalena CD, Tamara WK. Antenatal and postnatal depression - Are Polish midwives really ready for them?. Midwifery. 2020;83:102646. doi:10.1016/j.midw.2020.102646

4. Topalidou A, Thomson G, Downe S. COVID-19 and maternal mental health: Are we getting the balance right? 2020 Apr 6 [cited 2020 Jul 14]. Available from: https://www.medrxiv.org/content/10.1101/2020.03.30.20047969v1 DOI: 10.1101/2020.03.30.20047969

5. Arora KS, Mauch JT, Gibson KS. Labor and Delivery Visitor Policies During the COVID-19 Pandemic: Balancing Risks and Benefits. JAMA. 2020;323(24):2468-2469. DOI: 10.1001/jama.2020.7563

6. Das R. COVID 19, perinatal mental health and the digital pivot. Guildford: University of Surrey; 2020 Jun 8. 32p.

7. Mirzadeh M, Khedmat L. Pregnant women in the exposure to COVID-19 infection outbreak: the unseen risk factors and preventive healthcare patterns. J Matern Fetal Neonatal Med. 2020 Apr 7;1-2. DOI: 10.1080/14767058.2020.1749257 
8. Król A, Pustulka P. Women on strike: mobilizing against reproductive injustice in Poland. Int Fem J Polit. 2018 May 9;20(3):366-84. DOI: 10.1080/14616742.2018.1460214

9. WHO [Internet]. World Health Organization. Maternal mortality. 2018[cited 2020 Jul 14]. Available from: https://www.who.int/gho/maternal_health/mortality/maternal/en/

10. IMID[Internet]. Warsaw: Euro Peristat. Informacja prasowa Euro Peristat - IMID. 2019 Feb 13[cited $2020 \mathrm{Jul}$ 14]. Available from: https://www.europeristat.com/images/Informacja-Prasowa-EUROPERISTAT-IMiD-13.02.19.pdf

11. Szelewa D. Prawa reprodukcyjne w Europie i w Polsce: zakaz, kompromis, czy wybór? 2017[cited $2020 \mathrm{Jul}$ 14]. Available from: https://library.fes.de/pdf-files/bueros/warschau/14405.pdf

12. OECD[Internet]. Caesarean sections in selected countries 2017. 2019 Dec 9[cited 2020 Jul 14]. Available from: https://www.statista.com/statistics/283123/cesarean-sections-in-oecd-countries/

13. Dobrze Urodzeni [Internet].Chorzów: Niezależna Inicjatywa Rodziców i Położnych "Dobrze Urodzeni" - Stowarzyszenie. 2015[cited 2020 Jul 14]. Available from: https://www.dobrzeurodzeni.pl/statystyki.html

14. Baranowska B, Doroszewska A, Kubicka-Kraszyńska U, Pietrusiewicz J, Adamska-Sala I, Kajdy A et al. Is there respectful maternity care in Poland? Women's views about care during labor and birth. BMC Pregnancy Childbirth. 2019 Dec 23;19(520). [cited 2020 Jul 14]. Available from: https://bmcpregnancychildbirth.biomedcentral.com/articles/10.1186/s12884-019-2675-y\#citeas DOI: 10.1186/s12884-019-2675-y

15. WHO [Internet]. World Health Organization. 2020 COVID-19 : Resources for Pregnancy, Childbirth, Postnatal Care. [cited 2020 Jul 14]. Available from: https://www.who.int/maternal_child_adolescent/links/covid-19-mncah-resources-for-pregnancychildbirth-postnatalcare/en/

16. CDF [Internet]. Warszawa: Rodzić po Ludzku [eng. Childbirth with Dignity Foundation]. Opieka nad kobietą w okresie okołoporodowym w sytuacji zagrożenia epidemiologicznego. 2020 Mar 17 [cited $2020 \mathrm{Jul}$ 14]. Available from: https://www.rodzicpoludzku.pl/o-fundacji/interwencje2/1383-opiekanad-kobieta-w-okresie-okoloporodowym-w-sytuacji-zagrozenia-epidemiologicznego-2.html

17. PSGO[Internet]. Warsaw: Polish Society of Gynecologists and Obstetricians. Zalecenia Konsultanta Krajowego w dziedzinie Położnictwa i Ginekologii oraz Konsultanta Krajowego w dziedzinie Perinatologii dotyczące porodów rodzinnych. 2020 May 11[cited 2020 Jul 14]. Available from: https://www.gov.pl/web/zdrowie/zalecenia-dotyczace-porodow-rodzinnych

18. NHF [Internet]. Warszawa: Narodowy Fundusz Zdrowia. Poród rodzinny w czasie epidemii COVID-19. $2020 \mathrm{Jul}$ 10[cited $2020 \mathrm{Jul}$ 20]. Available from: https://www.nfz.gov.pl/aktualnosci/aktualnoscioddzialow/porod-rodzinny-w-czasie-epidemii-covid-19,414.html

19. Micelli E, Cito G, Cocci A, Polloni G, Russo Gl, Minervini A et al. Desire for parenthood at the time of COVID-19 pandemic: an insight into the Italian situation. Psychosom Obstet Gynaecol. 2020 May 7. Available from: https://www.tandfonline.com/doi/pdf/10.1080/0167482X.2020.1759545 DOI: 10.1080/0167482X.2020.1759545 
20. Corbett GA, Milne SJ, Hehir MP, Lindow SW, O'connell MP. Health anxiety and behavioural changes of pregnant women during the COVID-19 pandemic. Eur J Obstet Gynecol Reprod Biol. 2020;249:96-97. DOI:10.1016/j.ejogrb.2020.04.022

21. Viaux S, Maurice P, Cohen D, Jouannic JM. Giving birth under lockdown during the COVID-19 epidemic. J Gynecol Obstet Hum Reprod. 2020 May 11;49(6). DOI: 10.1016/j.jogoh.2020.101785

22. Mirzadeh M, Khedmat L. Pregnant women in the exposure to COVID-19 infection outbreak: the unseen risk factors and preventive healthcare patterns. J Matern Fetal Neonatal Med. 2020 Apr 7;1-2. DOI: $10.1080 / 14767058.2020 .1749257$

23. Rocca-Ihenacho $\mathrm{L}$, Alonso $\mathrm{C}$. Where do women birth during a pandemic? Changing perspectives on Safe Motherhood during the COVID-19 pandemic. J Glob Health Sci. 2020 Jun;2(1):e4. DOI: 10.35500/jghs.2020.2.e4

24. Durankus F, Aksu E. Effects of the COVID-19 pandemic on anxiety and depressive symptoms in pregnant women: a preliminary study. J Matern Fetal Neonatal Med. 2020 May 18[cited $2020 \mathrm{Jul} 14$ ]. Available from: https://www.tandfonline.com/doi/full/10.1080/14767058.2020.1763946 DOI: 10.1080/14767058.2020.1763946

25. Thomson G, Ebisch-Burton K, Flacking R. Shame if you do-shame if you don't: women's experiences of infant feeding. Matern Child Nutr. 2015 Jan;11(1):33-46. doi:10.1111/mcn.12148

26. Semaan A, Audet C, Huysmans E, Afolabi B, Assarag B, Banke-Thomas A et al. Voices from the frontline: findings from a thematic analysis of a rapid online global survey of maternal and newborn health professionals facing the COVID-19 pandemic. BMJ Global Health. 2020 May 11. [cited 2020 Jul 14]. Available from:

https://www.medrxiv.org/content/medrxiv/early/2020/05/11/2020.05.08.20093393.full.pdf DOI: 10.1136/bmjgh-2020-002967

27. Neale B. What is Qualitative Longitudinal Research? London: Bloomsbury Academic; 2019, 176p.

28. Denzin NK, Lincoln YS. The SAGE Handbook of Qualitative Research. Thousand Oaks: Sage Publications; 2005. 760p.

29. Saldana J. The Coding Manual for Qualitative Researchers $\left(3^{\text {rd }}\right)$. London: Sage; 2016, p.13.

\section{Figures}




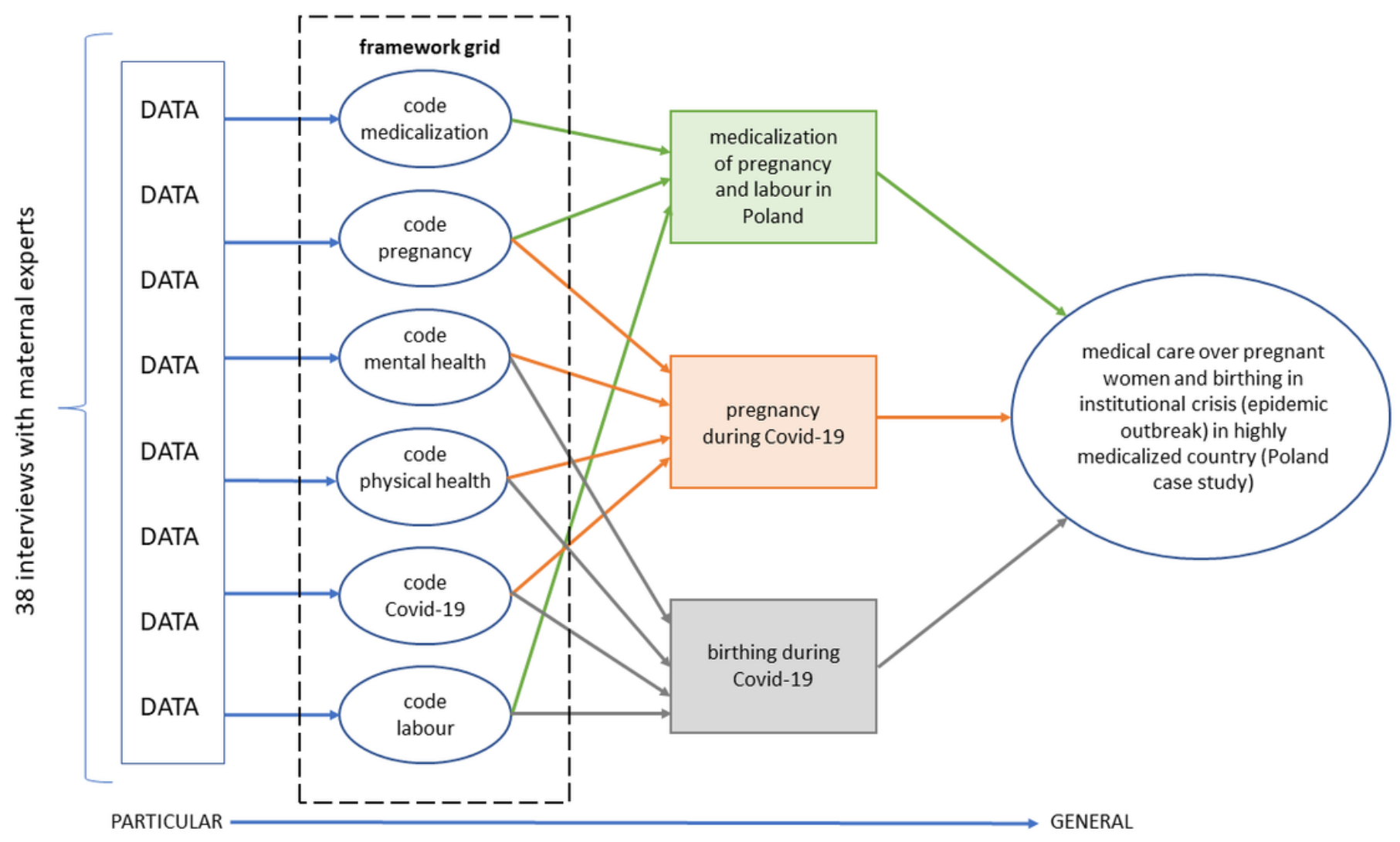

Figure 1

From data to findings

\section{Supplementary Files}

This is a list of supplementary files associated with this preprint. Click to download.

- 20201125blindedforreviewexpertguide.docx 